\title{
Endometriosis and ART outcome: a retrospective analysis
}

\author{
Janani S.*, Kundavi Shankar, Geetha V., Abdul Basith
}

Department of Reproductive Medicine, Madras Medical Mission, Chennai, Tamil Nadu, India

Received: 09 November 2020

Accepted: 12 January 2021

\section{*Correspondence:}

Dr. Janani S.,

E-mail: jananisuriyamoorthi@gmail.com

Copyright: (C) the author(s), publisher and licensee Medip Academy. This is an open-access article distributed under the terms of the Creative Commons Attribution Non-Commercial License, which permits unrestricted non-commercial use, distribution, and reproduction in any medium, provided the original work is properly cited.

\section{ABSTRACT}

Background: Endometriosis affects up to $30-40 \%$ of women seeking fertility treatment and is known to reduce fecundity. There remains a debate on the effect of endometriosis on the IVF outcome, with live birth not reported in most studies. This study looks at the impact of endometriosis on live birth rates after IVF and compares the chances of success with those without endometriosis.

Methods: Retrospective analysis of women who underwent IVF at our institution for 2 years were included. Multiple factor infertility, ovulation disorders and donor program were excluded. The outcomes were compared for 4 cohorts women with endometriosis, male factor infertility, tubal factor infertility and unexplained infertility. The primary outcome was live birth rate. Other outcome measures were total dose of gonadotropins used, mean number of oocytes collected, M2 oocyte rate, fertilization rate, implantation rate, and clinical pregnancy rate.

Results: Patients diagnosed with endometriosis had lower mean number of oocytes collected (6.86 vs 7.69, 7.94, 7.45 ) and lower mean number of M2 oocytes (5.31 vs $6.21,6.44,5.91)$ but was not statistically significant. Endometriosis patients required significantly higher dose of gonadotropins when compared to controls (5365.79 IU; p-0.001). The per ET implantation rate $(10.4 \%$ vs $17.8 \%, 22.5 \%, 19.2 \%)$, clinical pregnancy rate $(8 \%$ vs $15 \%, 20 \%$, $17 \%)$, live birth rate $(7.92 \%$ vs $16.6 \%, 15.14 \%, 12 \%)$ and the cumulative live birth rate $(27.9 \%$ vs $46.5 \%, 60 \%$, $46.7 \%$ ) were significantly less in women with endometriosis (p-0.039, p-0.021, p-0.001, p-0.039 respectively) and the effect is more pronounced with increasing disease severity.

Conclusions: Endometriosis affects all aspects of IVF outcomes including folliculogenesis, embryo development and implantation. Though ovarian factor can be overruled by increasing the stimulation doses as in our study, methods to improve the implantation rates should be thought about in future.

Keywords: Endometriosis, Implantation rate, Live birth rate, Oocytes rate

\section{INTRODUCTION}

Endometriosis affects up to $30-40 \%$ of subfertile women and it reduces fecundity. ${ }^{1}$ IVF outcome in endometriosis especially live birth is still a matter of debate. ${ }^{2}$

This study looks at the impact of endometriosis on live birth rates after IVF and compares the chances of success of women who have endometriosis with those with other factors of infertility.

\section{METHODS}

The patients who underwent ICSI-ET at our Institution during 2016 and 2017 were retrospectively analyzed. After excluding women with multiple factor infertility, ovulation disorders and donor programmes, the total number of women analysed were 301, which included women with either endometriosis, male factor infertility, tubal factor infertility or unexplained infertility. The patients were divided into 4 groups - women with endometriosis $(n=70)-23.3 \%$, women with male factor infertility $(n=109)-36.2 \%$, women with tubal factor 
infertility $(n=66)-21.9 \%$ and women with unexplained infertility $(n=56)-18.6 \%$. The patients in the endometriosis group were scored according to the revised classification of the American Fertility Society after laparoscopy. These patient's records were analysed from the start of the stimulation cycle and the data were collected for all the frozen embryo transfers they underwent with the embryos collected in that stimulation cycle. Baseline day 2 ovarian reserve tests (AMH, AFC, FSH) were done for all the patients. Fixed antagonist protocol was used for stimulation. Gonadotropins were started at a dose of 150 IU to 300 IU based on the patient's profile. Ovulation was triggered when three or more follicles reached $\geq 18 \mathrm{~mm}$ using human chorionic gonadotropin (HCG) /Inj. Decapeptyl/dual trigger. Oocyte retrieval was done after 35 hours of the trigger. ICSI was done for all the patients and embryos were frozen. Endometriosis patients were given 8 weeks of $\mathrm{GnRH}$ analogue for pituitary down-regulation. Embryo transfer was done in the subsequent cycle when the endometrial thickness was $\geq 8 \mathrm{~mm}$. Serum Beta HCG was done on 16th day of embryo transfer. Pregnancy was confirmed by the transvaginal ultrasound after 2 weeks of positive Beta HCG test.

\section{Outcome measures}

The primary outcome measured was the cumulative live birth rate in all patients. The secondary outcome measures were the mean dose of gonadotropins used, mean number of oocytes retrieved, mean number of M2 oocytes, fertilisation rate, implantation rate, clinical pregnancy rate.

\section{RESULTS}

The patients in all the 4 groups were comparable in terms of age, BMI, type of infertility (primary or secondary) and duration of infertility (Table 1, Figure 1).

Table 1: Mean age and BMI.

\begin{tabular}{|lll|}
\hline $\begin{array}{l}\text { Type of } \\
\text { infertility }\end{array}$ & $\begin{array}{l}\text { Mean age } \\
\text { (years) }\end{array}$ & $\begin{array}{l}\text { Mean BMI } \\
\mathrm{Kg} / \mathrm{m}^{2}\end{array}$ \\
\hline Endometriosis & $33.7(23-40)$ & $24.68(18.1-35)$ \\
\hline Male factor & $33.6(25-41)$ & $23.77(17-34.3)$ \\
\hline Tubal factor & $32.5(21-38)$ & $23.5(19.4-31)$ \\
\hline $\begin{array}{l}\text { Unexplained } \\
\text { infertility }\end{array}$ & $32.3(22-37)$ & $22.79(18-29.5)$ \\
\hline
\end{tabular}

The mean AMH and antral follicle count were significantly reduced in women with endometriosis when compared to other factors (p-0.03 and p-0.009 respectively) (Table 2 ).

When endometriosis women were classified according to ASRM classification, number of women with stage 1 endometriosis were $(n=14)-20 \%$, stage $2(n=13) 18.6 \%$, stage $3(n=24)-34.3 \%$, stage $4(n=19)-27 \%$ (Figure 2$)$.

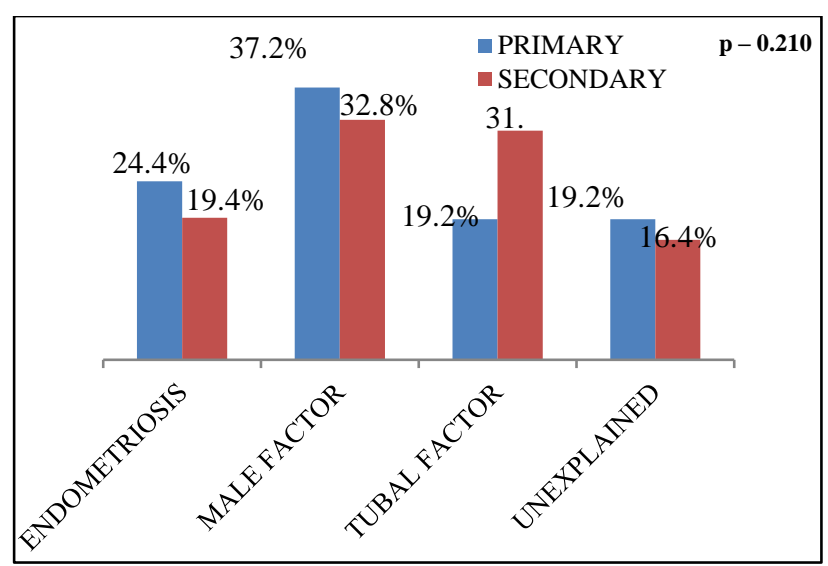

Figure 1: Type of infertility.

Among women with endometriosis, 61.4\% (n=43) had ovarian endometrioma of which $74.4 \%(n=32)$ underwent cystectomy (Figure 3). Women who underwent cystectomy had significantly reduced mean AMH (1.2 vs $2.6 \mathrm{ng} / \mathrm{dl})$, antral follicle count (7.2 vs 12.5) and mean number of M2 oocytes (4.1 vs 6.54) when compared to those who did not undergo cyst excision ( $\mathrm{p}-0.043, \mathrm{p}$ $0.021, \mathrm{p}-0.035$ respectively). But other ART outcomes like fertilization rate $(89.3 \%$ vs $90.6 \%$; $\mathrm{p}-0.09)$, implantation rate $(18.03 \%$ vs $17.8 \%$; p-0.12), clinical pregnancy rate $(17.9 \%$ vs $17.5 \%$; p- 0.22$)$, live birth rate (14.75\% vs $14.27 \%$; p-0.10) showed no difference (Table 3 ). Endometriosis patients required a higher mean dose of gonadotropins (5365.79 IU; p-0.001) when compared to other factors of subfertility (Table 4). There was no difference in the type of trigger used among the groups. Mean number of oocytes retrieved (6.86 vs 7.69, 7.94, 7.45), mean number of M2 oocytes (5.31 vs $6.21,6.44$, $5.91)$ and the fertilization rate $(72.3 \%$ vs $73.8 \%, 75.1 \%$, $74 \%$ ) were comparable among the groups (p-0.47, p-0.33, $\mathrm{p}-0.255$ respectively) (Table 5 ). There was no difference in the day of transfer (day 2/day 3), the number of embryos and the grade of embryos transferred. The per ET implantation rate $(10.4 \%$ vs $17.8 \%, 22.5 \%, 19.2 \%)$, clinical pregnancy rate $(8 \%$ vs $15 \%, 20 \%, 17 \%)$, live birth rate per ET $(7.92 \%$ vs $16.6 \%, 15.14 \%, 12 \%)$ and the cumulative live birth rate $(27.9 \%$ vs $46.5 \%, 60 \%, 46.7 \%)$ were significantly less in women with endometriosis ( $\mathrm{p}$ $0.039, \mathrm{p}-0.021, \mathrm{p}-0.001, \mathrm{p}-0.039$ respectively) (Figure 4 , $5,6,7)$.

Table 2: Mean AMH and Antral follicle count.

\begin{tabular}{|lll|}
\hline $\begin{array}{l}\text { Type of } \\
\text { infertility }\end{array}$ & Mean AMH (ng/dl) & Mean AFC \\
\hline Endometriosis & 2.28 & 12.2 \\
\hline Male factor & 2.80 & 14.1 \\
\hline Tubal factor & 2.96 & 16.3 \\
\hline $\begin{array}{l}\text { Unexplained } \\
\text { infertility }\end{array}$ & 3.00 & 14.3 \\
\hline P value & 0.03 & 0.009 \\
\hline
\end{tabular}




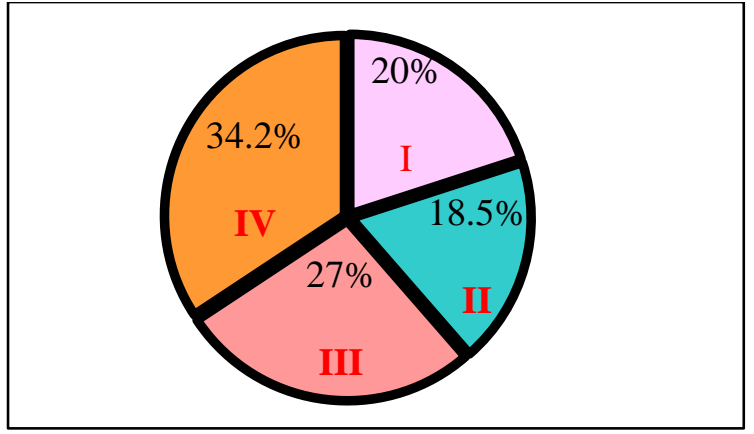

Figure 2: Stages of endometriosis.

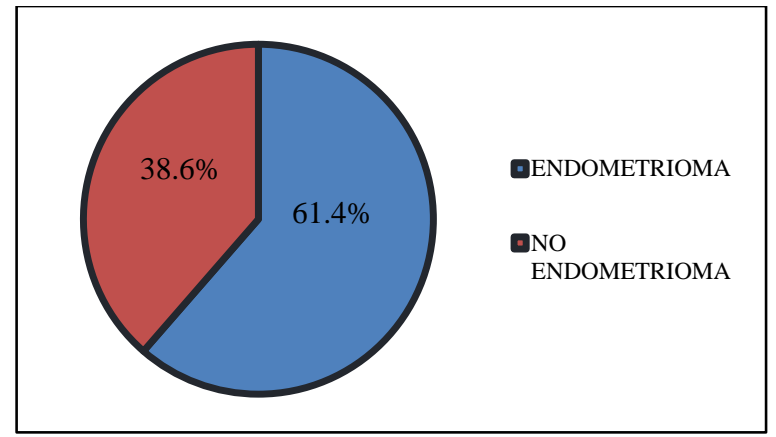

Figure 3: Endometrioma vs no endometrioma.

Table 3: Comparison of mean AMH, mean AFC, mean number of M2 oocytes, fertilization rate, implantation rate, clinical pregnancy rate and live birth rate between women with endometrioma who underwent cystectomy and those who underwent IVF programme with intact endometrioma.

\begin{tabular}{|lllllllll|}
\hline $\begin{array}{l}\text { IVF } \\
\text { programme }\end{array}$ & $\begin{array}{l}\text { Mean AMH } \\
(\mathbf{n g} / \mathbf{m l})\end{array}$ & $\begin{array}{l}\text { Mean } \\
\text { AFC }\end{array}$ & $\begin{array}{l}\text { Mean M2 } \\
\text { oocyte }\end{array}$ & $\begin{array}{l}\text { Fert rate } \\
(\%)\end{array}$ & $\begin{array}{l}\text { IMP Rate } \\
(\boldsymbol{\%})\end{array}$ & $\begin{array}{l}\text { Clin } \\
\text { Preg rate }(\boldsymbol{\%})\end{array}$ & $\begin{array}{l}\text { LBR } \\
(\%)\end{array}$ & $\begin{array}{l}\text { CLBR } \\
(\%)\end{array}$ \\
\hline Cystectomy & 1.2 & 7.2 & 4.1 & 89.3 & 18.03 & 17.9 & 14.75 & 25.7 \\
\hline Intact cyst & 2.6 & 12.5 & 6.54 & 90.6 & 17.8 & 17.5 & 14.28 & 29.4 \\
\hline P value & 0.043 & 0.021 & 0.035 & 0.09 & 0.12 & 0.22 & 0.10 & 0.075 \\
\hline
\end{tabular}

Table 4: Mean dose of gonadotropins used among the groups.

\begin{tabular}{|ll|}
\hline Type of infertility & $\begin{array}{l}\text { Mean dose of } \\
\text { gonadotropins (IU) }\end{array}$ \\
\hline Endometriosis & 5365.79 \\
\hline Male factor & 3721.32 \\
\hline Tubal factor & 3663.21 \\
\hline Unexplained infertility & 3501 \\
\hline P value & 0.001 \\
\hline
\end{tabular}

Table 5: Mean number of M2 oocytes and fertilization rate among the groups.

\begin{tabular}{|llll|}
\hline & $\begin{array}{l}\text { Mean } \\
\text { no of } \\
\text { oocytes }\end{array}$ & $\begin{array}{l}\text { Mean no } \\
\text { of M2 } \\
\text { oocytes }\end{array}$ & $\begin{array}{l}\text { Fertilization } \\
\text { rate }\end{array}$ \\
\hline Endometriosis & 6.86 & 5.31 & $72.3 \%$ \\
\hline Male factor & 7.69 & 6.21 & $73.8 \%$ \\
\hline Tubal factor & 7.94 & 6.44 & $75.1 \%$ \\
\hline $\begin{array}{l}\text { Unexplained } \\
\text { infertility }\end{array}$ & 7.45 & 5.91 & $74 \%$ \\
\hline P value & 0.47 & 0.33 & 0.255 \\
\hline
\end{tabular}

The implantation rate, clinical pregnancy rate, live birth rate were significantly lesser as the stage of the endometriosis becomes more advanced. The per transfer implantation rates for stage 1 was $25 \%$, stage $2-11.8 \%$, stage $3-8.8 \%$ and stage $4-5.1 \%$ (p-0.013), clinical pregnancy rate $(24.2 \%$ vs $11.7 \%, 8.5 \%, 4.1 \%$; p - 0.009) and the live birth rate $(18.7 \%$ vs $11.7 \%, 8.8 \%, 3.8 \% ; \mathrm{p}-$ 0.017) (Figure 8).

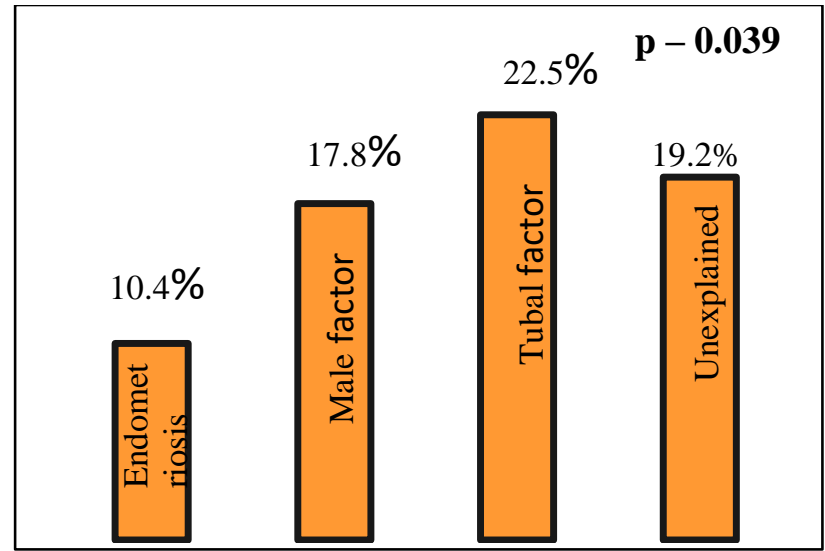

Figure 4 Implantation rate per embryo transfer among the groups

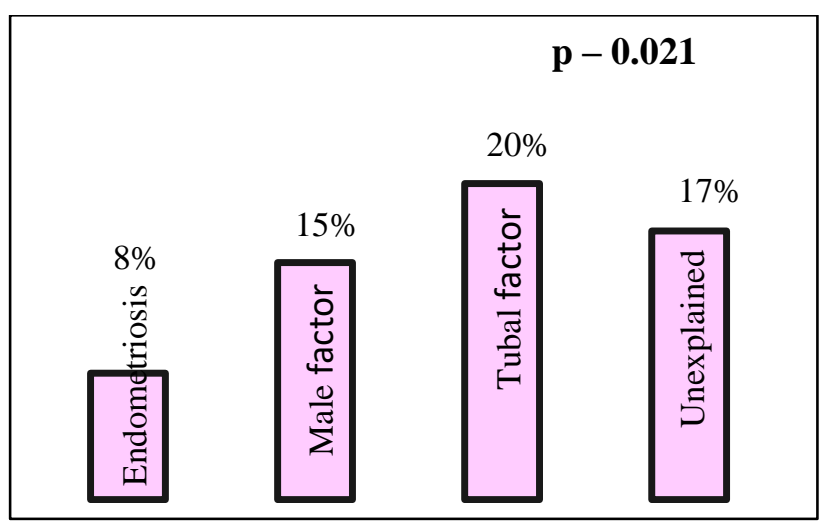

Figure 5: Clinical pregnancy rate per embryo transfer among the groups. 


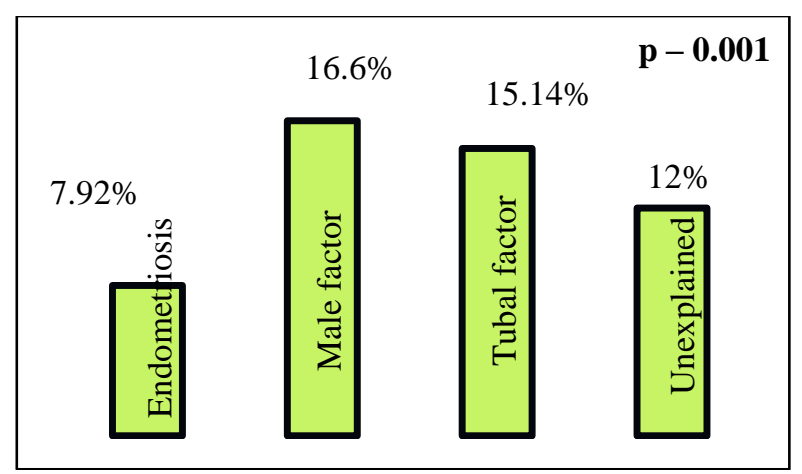

Figure 6: Live birth rate per embryo transfer among the groups.

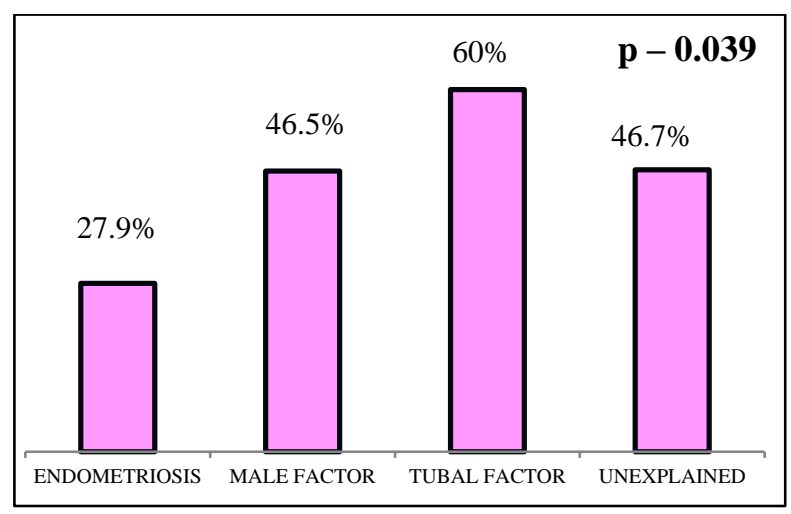

Figure 7: Cumulative live birth rate among the groups.

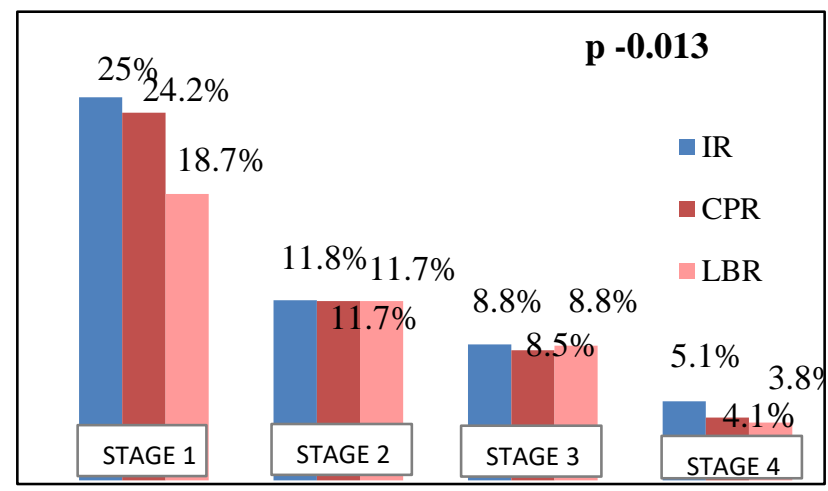

Figure 8: Implantation rate, clinical pregnancy rate and live birth rate among various stages of endometriosis.

Women who conceived with endometriosis had more placental problems like intrauterine growth restriction $(10 \%)$, placenta previa (8\%), pre-eclampsia $(5.7 \%)$ and abruption $(1.4 \%)$ but was not statistically significant when compared with other groups.

\section{DISCUSSION}

There are conflicting results in various studies which have compared endometriosis with other factors. The cumulative live birth rate is considered to be the most relevant outcome in ART. The findings of our study showed that endometriosis patients had decreased ovarian reserve, required more amount of gonadotropins, but there was no difference in the mean number of M2 oocytes and fertilization rate when compared to other groups, whereas the implantation rate, clinical pregnancy rate and cumulative live birth rate were significantly less in endometriosis patients. A large prospective analysis found no difference in the cumulative live birth rate between endometriosis and other factors of infertility. ${ }^{1}$ In their study, they had decreased oocyte yield in endometriosis patients but no difference in the cumulative live birth rate and suggested a predominant effect of endometriosis on oocyte yield rather than on endometrial environment since their cumulative live birth rates were comparable. But the prevalence of endometriosis in their study cohort was only $6 \%$ whereas in our study it is $23.3 \%$ and they have not compared the outcomes among various stages of endometriosis.

Generally, women with endometriosis without a history of ovarian surgery do not have lower ovarian reserve parameters compared to control women. ${ }^{3,4}$ In the present study, patients with endometriosis presented with a reduced ovarian reserve and required significantly higher total dose of gonadotropins. This could be due to more number of women with advanced-stage disease (61.1\%; $\mathrm{n}=43$ ) in our study. Previously, endometriosis has been associated with reduced oocyte quality and embryonic development.5,6 Later studies showed that the predominant effect of endometriosis was on the oocytes yield rather than on endometrial environment as there was no difference in the fertilisation rates in women with and without endometriosis. ${ }^{1}$ In the present study, the oocyte yield, number of M2 oocytes, fertilisation rate and the quality of embryos were comparable among the groups but the implantation rate, clinical pregnancy rate and live birth rate were significantly reduced which confirms the adverse effect of endometriosis on implantation.

\section{CONCLUSION}

Endometriosis affects all aspects of IVF outcomes including folliculogenesis, embryo development and implantation. Though ovarian factor can be overruled by increasing the stimulation doses as in our study, methods to improve the implantation rates should be thought about in future.

\section{ACKNOWLEDGMENTS}

Authors would like to thank the statistician $\mathrm{Mr}$. Porchelvan and Embryologist Dr. Yamini for their support during study.

\section{Funding: No funding sources}

Conflict of interest: None declared

Ethical approval: The study was approved by the Institutional Ethics Committee 


\section{REFERENCES}

1. Feichtinger M, Nordenhök E, Olofsson JI, Hadziosmanovic N, Wallberg KA. Endometriosis and cumulative live birth rate after fresh and frozen IVF cycles with single embryo transfer in young women: no impact beyond reduced ovarian sensitivity-a case control study. J Assist Reprod Genet. 2019;36(8):1649-1656.

2. Muteshi CM, Ohuma EO, Child T, Becker CM. The effect of endometriosis on live birth rate and other reproductive outcomes in ART cycles: a cohort study. Human Reproduction Open. 2018;4:2018.

3. Hanege YB, Çekıç GS, Ata B. Endometrioma and ovarian reserve: effects of endometriomata per se and its surgical treatment on the ovarian reserve. Facts Views Vis Obgyn. 2019;11(2):151-7.
4. Chiang HJ, Lin PY, Huang FJ. The impact of previous ovarian surgery on ovarian reserve in patients with endometriosis. BMC Womens Health. 2015;15:74.

5. Sanchez AM, Vanni VS, Bartiromo L. Is the oocyte quality affected by endometriosis? A review of the literature. J Ovarian Res. 2017;10(1):43.

6. $\mathrm{Xu} \mathrm{B}$, Guo N, Zhang XM. Oocyte quality is decreased in women with minimal or mild endometriosis. Sci Rep. 2015;5:10779.

Cite this article as: Janani S, Shankar K, Geetha V, Basith A. Endometriosis and ART outcome: a retrospective analysis. Int J Reprod Contracept Obstet Gynecol 2021;10:536-40. 